\title{
Article
}

\section{Industrial Dust Explosions. A Brief Review}

\author{
Rolf K. Eckhoff ${ }^{1, *}$ and Gang $\mathrm{Li}^{2}$ \\ 1 Department of Physics \& Technology, University of Bergen, NO-5020 Bergen, Norway \\ 2 Fire and Explosion Protection Laboratory, Northeastern University, Shenyang 110819, China; \\ ligang@mail.neu.edu.cn \\ * Correspondence: rolf.eckhoff@uib.no
}

check for updates

Citation: Eckhoff, R.K.; Li, G. Industrial Dust Explosions. A Brief Review. Appl. Sci. 2021, 11, 1669. https://doi.org/10.3390/app11041669

Academic Editor: Adrian Irimescu

Received: 21 December 2020

Accepted: 27 January 2021

Published: 12 February 2021

Publisher's Note: MDPI stays neutral with regard to jurisdictional claims in published maps and institutional affiliations.

Copyright: (c) 2021 by the authors. Licensee MDPI, Basel, Switzerland. This article is an open access article distributed under the terms and conditions of the Creative Commons Attribution (CC BY) license (https:// creativecommons.org/licenses/by/ $4.0 /)$.

\begin{abstract}
This paper first addresses the question: what is a dust explosion? Afterwards, some specific issues are briefly reviewed: materials that can give dust explosions, factors influencing ignitability and explosibility of dust clouds, the combustion of dust clouds in air, ignition sources that can initiate dust explosions, primary and secondary dust explosions, dust flash fires, explosions of "hybrid mixtures", and detonation of dust clouds. Subsequently, measures for dust explosion prevention and mitigation are reviewed. The next section presents the case history of an industrial dust explosion catastrophe in China in 2014. In the final section, a brief review is given of some current research issues that are related to the prevention and mitigation of dust explosions. There is a constant need for further research and development in all the areas elucidated in the paper.
\end{abstract}

Keywords: dust explosions; dust cloud ignition; primary and secondary dust explosions; explosion prevention; explosion mitigation; recent dust explosion research

\section{Brief Review of Dust Explosion Basics}

\subsection{What Is a Dust Explosion?}

The phenomenon named dust explosion is quite simple and easy to envisage in terms of daily life experience. Figure 1a illustrates how a piece of wood, once ignited, burns quite slowly, releasing its heat over a comparatively great time span. However, when cut into small pieces, as illustrated in Figure 1b, the combustion rate of the wood increases, because the total contact surface area between wood and air has increased. Very fast combustion can take place if the wood is sub divided further right down to small particle sizes of max. $0.1 \mathrm{~mm}$, and the particles are dispersed in the air as a very dense cloud that becomes ignited. Figure 1c illustrates this situation. If the cloud is fully or partly confined, the fire can produce a sufficient pressure for the confinement walls to burst, and a "bang" is emitted into the surroundings. This is a genuine dust explosion.

\subsection{Materials That Can Give Dust Explosions}

$$
\text { fuel }+ \text { oxygen } \rightarrow \text { oxides }+ \text { heat }
$$

Most often, the rapid energy that is released in a dust explosion is governed by the chemical reaction:

Therefore, only materials that are not already stable oxides can give dust explosions. This excludes silicates, sulphates, nitrates, carbonates, and phosphates, and, therefore, dust clouds of Portland cement, sand, limestone, etc. cannot give dust explosions. The main four groups of materials that can give such explosions are:

- $\quad$ natural organic materials (grain, wood, linen, sugar, etc.);

- $\quad$ synthetic organic materials (plastics, organic pigments, pesticides, pharmaceuticals, etc.);

- coal and peat; and, 
- $\quad$ metals (aluminium, magnesium, titanium, zinc, iron, etc.).

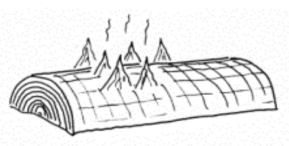

(a) slow combustion

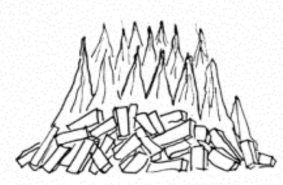

(b) fast combustion

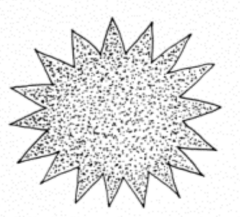

(c) dust explosion

Figure 1. Illustration of the increase of the combustion rate of a given mass of combustible solid with increasing sub-division. From Eckhoff [1-3]. Copyright (2019), with permission from Elsevier.

\subsection{Factors Influencing Ignitability and Explosibility of Dust Clouds}

A list of factors influencing the ignitability and explosibility of dust clouds may appear, as follows:

a. Chemical composition of dust including moisture content.

b. Chemical composition, and initial pressure and temperature of the gas phase in which the dust is dispersed.

c. Distributions of particle sizes and shapes in the dust (determine the specific surface area of the dust in the fully dispersed state).

d. Degree of agglomeration, of dust particles, determining the effective specific surface area available to the combustion process in the dust cloud in the actual industrial situation.

e. Distribution of dust concentration in the actual cloud.

f. Distribution of initial turbulence in the actual cloud.

g. Possibility of generation of explosion-induced turbulence in the still unburnt part of the cloud (location of ignition source an important parameter).

h. Possibility of flame front distortion by other mechanisms than turbulence.

i. Possibility of significant radiative heat transfer (highly dependent on flame temperature, which in turn depends on particle chemistry).

Factors $a, b, c$, and perhaps $i$ can be regarded as the basic parameters of the explosive dust cloud. However, factors $d$ to $h$ are influenced by the actual industrial dust cloud generation process and explosion development.

\subsection{Combustion of Dust Clouds in Air}

\subsubsection{Explosible Concentration Ranges of Dust Clouds in Air}

The explosive combustion of dust clouds, as illustrated in Figure 1c, cannot take place unless the mass of dust per unit volume of dust clouds is within certain limits. Figure 2 illustrates the explosible range of a typical natural organic material (maize starch) in air at ambient conditions. 


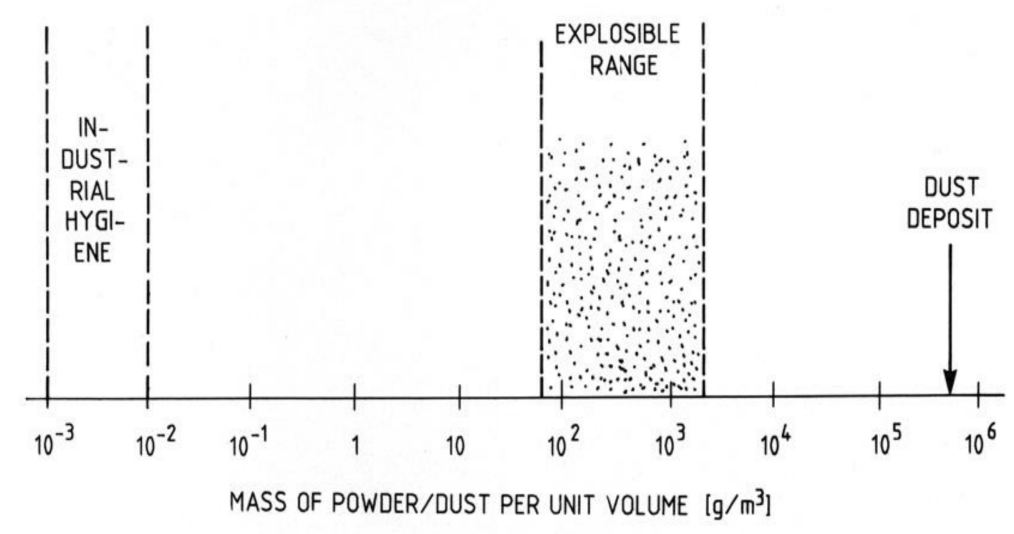

Figure 2. The range of explosible dust concentrations in air at normal temperature and atmospheric pressure for a typical natural organic dust (maize starch). A comparison with typical range of maximum permissible dust concentrations in the context of industrial hygiene, and a typical density of deposits of natural organic dusts. From Eckhoff [1-3]. Copyright (2019), with permission from Elsevier.

The explosibility limits differ for various dust materials. For example, zinc powder has a minimum explosible concentration in air of approximately $500 \mathrm{~g} / \mathrm{m}^{3}$.

The unpleasant dust concentrations that sometimes occur in general working atmospheres in factories and call the attention of industrial hygiene authorities are orders of magnitude lower than the minimum explosible concentrations, as also illustrated in Figure 2.

Therefore, sufficiently dense dust clouds in which dust explosions can be initiated are practically always located inside process equipment, such as mills, mixers, screens, dryers, cyclones, filters, bucket elevators, hoppers, silos, aspiration ducts, and pipes for pneumatic transport of powders. Such explosions are called primary explosions.

However, as discussed in Section 1.6, below, primary dust explosions can give rise to much more severe secondary dust explosions and flash fires outside process equipment.

\subsubsection{Flame Propagation Processes in Dust Clouds}

A cloud in air of a given dust can burn with widely different combustion rates, depending on the dust concentration in the cloud, the cloud turbulence, and the degree of dust dispersion in the cloud in the actual industrial situation. The turbulence of explosible dust clouds strongly influences both the ignitability and explosibility of the clouds. Most often, combustion rates increase and ignition sensitivities (e.g., sensitivity to electric/electrostatic spark ignition) decrease as turbulence increases.

Generally, the reaction zones of dust cloud flames are thicker (typically 5-100 mm) than premixed-gas flames. Contrary to flame propagation in transparent gas mixtures, radiative heat transfer from the flame front to the unburnt cloud ahead of the flame can be important in large-scale flame propagation in some dust clouds of high flame temperatures. Leuschke [4] demonstrated the experimental ignition of clouds in air of $\mathrm{Zr}, \mathrm{Ti}, \mathrm{Al}$, and $\mathrm{Mg}$ dust clouds in air by radiative heat transfer from flames in neighbouring identical dust clouds.

\subsubsection{Influence of Dust Chemistry, Dust Particle Size, and Dust Moisture Content}

As discussed by Eckhoff [1] dust chemistry and dust particle size influence both the ignition sensitivity and explosion violence of explosible dust clouds. The heat of combustion of a solid material per mole of oxygen consumed is a useful parameter for comparing the potential explosion powers of various dust materials. $\mathrm{Mg}$ and $\mathrm{Al}$ top the list, whereas natural organic materials have much lower values. This is why flames of burning clouds in air of $\mathrm{Mg}$ and $\mathrm{Al}$ dusts are almost white, whereas those of burning clouds air of natural organic materials are orange. 
For most dust materials, both ignition sensitivity and explosion violence of explosible dust clouds increase with decreasing dust particle size down to about $1 \mu \mathrm{m}$. Moisture in the dust reduces both dust cloud ignition sensitivity and explosion violence. Several mechanisms contribute to this [1].

\subsection{Ignition Sources That Can Start Dust Explosions}

\subsubsection{Smouldering or Burning 'Nests'}

Combustible dusts, when deposited in heaps or layers, may develop internal smouldering combustion nests of high temperatures. Some natural vegetable materials of high fat and/or moisture content may develop spontaneous combustion, even from normal ambient temperatures, due to biochemical activity. If such a hot reaction zone, which is often called a "smouldering nest", makes contact with an explosive dust cloud, a dust explosion may be initiated.

\subsubsection{Open Flames, Hot Surfaces and Mechanical Impacts}

Flames of welding and cutting burners are more than sufficiently powerful to initiate explosions in most explosible dust clouds. Hot surfaces, e.g., overheated bearings, heaters in workrooms, light bulbs, and walls in dryers, can initiate dust explosions directly by contact with the dust cloud.

Mechanical impacts are short-duration interactions between two solid bodies under the conditions of large transient mechanical forces. If the impacting metal is hard, small fragments may be torn off and start burning in air due to the initial heat absorbed by the particle in the impact. In other cases, impacts can occur repeatedly at one specific point, creating a hot surface that may be capable of igniting an explosible dust cloud contacting the hot spot.

\subsubsection{Electric and Electrostatic Sparks}

There are two types of electric spark discharges. The first is inductive sparks/arcs generated when live electric circuits are broken, either accidentally or intentionally (e.g., in switches). If the current in the circuit prior to rupture is $i$ and the circuit inductance is $L$, the theoretical spark energy, neglecting external circuit losses, will be $\frac{1}{2} L i^{2}$. Capacitive spark discharges occur when electrostatic charge that has accumulated on electrically conducting, unearthed objects is discharged to earth across an air gap between two electrically conducting electrodes. If the capacitance is $C$ and the voltage to which it has been charged is $U$, then the theoretical energy in the capacitor is $\frac{1}{2} C U^{2}$. Glor [5] and Lüttgens and Glor [6] described five other types of electrostatic discharges than spark discharges. Of these, only propagating brush discharges and discharges along the surface of powder/dust in bulk are considered to be able to ignite dust clouds in air. Propagating brush discharges can be particularly energetic and hazardous.

\subsubsection{Jets of Hot Combustion Products, Shock Waves, and Light Radiation}

Referring to the doctorate thesis of Schuber, Bartknecht [7] adapted the concept of "maximum experimental safe gap" (MESG), which is used with explosive gases (explained in Eckhoff [2]) to predict whether dust explosions could be transmitted through narrow gaps in process units, e.g., rotary locks. Other researchers have studied ignition of explosible dust clouds by a shock wave passing through the cloud. Proust [8] ignited explosible dust clouds by a beam of laser light conveyed through an optical fibre. However, the minimum ignition energies obtained were then several orders of magnitude larger than the corresponding minimum ignition energies by electrical sparks.

\subsection{Primary and Secondary Dust Explosions, and Dust Flash Fires}

\subsubsection{Definition of Primary and Secondary Dust Explosions}

Dust explosions in the process industries most often start inside some process unit. Such explosions are often named primary dust explosions. In dust explosion mitigation it 
is a central concern to limit the extent of primary dust explosions to the particular process unit where the explosion started. However, this is not always accomplished, and more severe secondary dust explosions outside process equipment can result.

The first step in the process leading to secondary dust explosions outside process equipment is the entrainment of dust layers that have accumulated there, by the blast wave from the primary explosion. The second step is the ignition of this secondary cloud by the flame from the primary dust explosion following the blast wave. Numerous accident histories have shown that secondary dust explosions can kill and hurt people and cause severe damage to process plants and buildings.

\subsubsection{The Hazard of Even Very Thin Dust Layers}

Figure 2 in Section 1.4.1 illustrates that there is a gap of approximately two orders of magnitude between the maximum explosible dust concentration and the bulk density of a dust layer. Figure 3 illustrates the consequence of this with regard to the volume of dust cloud that may be generated by a given volume of dust layer.

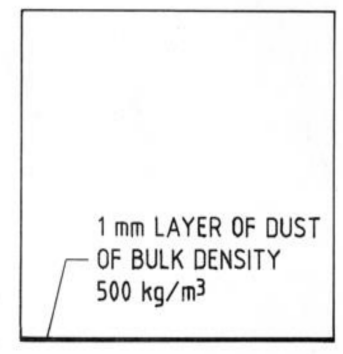

(a)

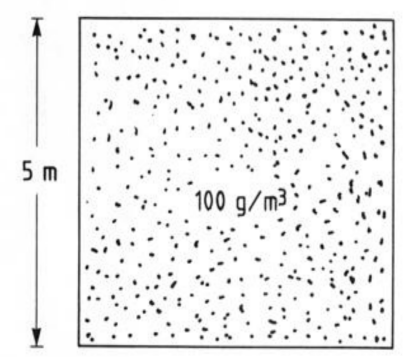

(b)

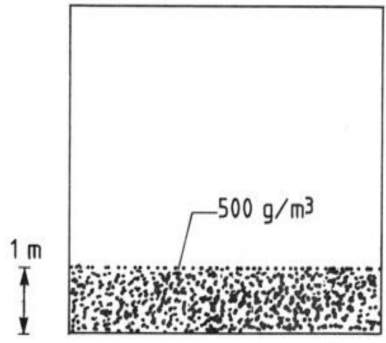

(c)

Figure 3. Illustration of the potential secondary-dust-explosion hazard of even thin dust layers. (a) Illustrates that a $1 \mathrm{~mm}$ thick dust layer of a dust of bulk density $500 \mathrm{~kg} / \mathrm{m}^{3}$ will, as (b) illustrates, generate a cloud of average concentration $100 \mathrm{~g} / \mathrm{m}^{3}$, if dispersed in a room of $5 \mathrm{~m}$ height. As illustrated in (c), dispersion to only $1 \mathrm{~m}$ cloud height will give $500 \mathrm{~g} / \mathrm{m}^{3}$, i.e. in the middle of the explosible range. From Eckhoff [1-3]. Copyright (2019), with permission from Elsevier.

The simple relationship between the dust concentration $c$ and bulk density of the dust layer $\rho_{b u l k}$, the layer thickness $h$, and the height $H$ of the dust cloud produced from the layer, is:

$$
c=\rho_{\text {bulk }}(h / H)
$$

If a dust layer of thickness $h$ on the internal wall of a cylindrical duct of diameter $D$ is homogeneously dispersed over the whole duct cross-section, one has:

$$
c=\rho_{\text {bulk }}(4 h / D)
$$

With a duct diameter of $0.2 \mathrm{~m}$, which is typical of many dust extraction ducts in industry, the dispersion of a dust layer of a thickness of only $0.1 \mathrm{~mm}$ and bulk density $500 \mathrm{~kg} / \mathrm{m}^{3}$, typical of many natural organic dusts, will generate a dust concentration of about $1000 \mathrm{~g} / \mathrm{m}^{3}$. Therefore, even thin layers of potentially explosible dusts in process plants are a potential hazard of hazardous secondary dust explosions, as illustrated by the course of development of the major dust explosion catastrophe in China in 2014, discussed in Section 3 of this paper.

\subsubsection{Flash Fires in Secondary Dust Clouds outside Process Equipment}

Secondary dust explosions occur when a secondary dust flame creates a sufficient pressure increase to cause the destruction of building structures, etc. However, in some cases, the burning of the secondary dust cloud may not produce a sufficient pressure 
increase for causing this kind of destruction. Such events are named dust cloud flash fires. They may propagate long distances throughout a factory without causing any significant damage to the building structures. However, they present a serious fire hazard to both people and any combustible material that they may touch on their way. When smoke and hot air resulting from flash fires are inhaled, serious damage to human lung tissue can result.

\subsection{Explosion of "Hybrid Mixtures"}

\subsubsection{Definition of a "Hybrid Mixture"}

In a process safety context, Bartknecht [9] was probably first researcher to introduce the concept of "hybrid mixture. His main focus then was on explosible dust clouds in air that also contained a small fraction of combustible gas/vapour, of a concentration below the lower explosibility limit in air of the gas/vapour itself.

\subsubsection{Explosions of "Hybrid" Mixtures}

The earliest experimental investigation traced of the ignitability and explosibility of dust clouds that are dispersed in air containing a small fraction of explosive gas, is the one by Engler [10]. Two decades later, Engler [11] described a laboratory-scale experiment, in which the "hybrid" effect was more clearly demonstrated.

More recently, Nagy and Portman [12] studied the "hybrid" effect of adding small percentages of methane to the air, in which coal dust cloud was generated, on the explosion violence of the cloud Franke [13] investigated the influence of small fractions of methane in the air on the minimum electric spark ignition energy (MIE) of coal dust clouds. Pellmont [14] demonstrated the hybrid effect on MIEs of clouds of various dusts when the air was mixed with small amounts of propane Addai et al. [15]. measured the minimum ignition temperature (MIT) and minimum explosible dust concentration (MEC) of hybrid mixtures of a combustible dust that was dispersed in a mixture of air and a small fraction of an explosive gas/vapour.

\subsection{Detonation of Dust Clouds}

As for premixed gases, detonation in explosive dust clouds is a singular, extreme mode of flame propagation through the cloud. Subsequently, the transfer of heat in the flame front, from the burning to the unburnt dust cloud, is not by heat conduction and convection and thermal radiation, characteristic of the deflagration mode of explosion propagation. In a dust cloud detonation, heat is transferred by an extremely fast compression of the unburnt dust cloud just ahead of the hot reaction zone propagating at supersonic speed. Therefore, detonation in a dust cloud can only be initiated by a sufficiently strong shock wave, either from the detonation of an explosive charge inside the cloud, or by a gradual build-up of a strong shock front by turbulent acceleration of the explosion itself in e.g., long ducts (Deflagration-to-Detonation-Transition, DDT). Tulis [16] provided direct experimental evidence of a self-sustained detonation wave being able to travel through an unconfined cloud in air of fine aluminium dust.

\section{Dust Explosion Prevention and Mitigation}

\subsection{Preventing Explosible Dust Clouds}

2.1.1. Adding Clean Inert Gas

For a given type of dust suspended in air, and a given type of added inert gas, there is a "limiting oxygen concentration" (LOC) in the air/gas mixture, below which the dust cloud is unable to propagate a self-sustained flame. By keeping the oxygen content below this limit throughout the process system, the possibility of dust explosions is excluded. Four types of inert gases are currently in use for this purpose, viz. carbon dioxide, water vapour, nitrogen, and rare gases. The design of gas inerting systems depends on whether the process is continuous or of the batch type. It also depends on the strength of the process 
equipment, and on type and source of inert gas. Two main system principles are used, viz. pressure-variation and flushing.

\subsubsection{Intrinsic Inerting}

'Intrinsic inerting' means that the required quantity of inert gas is produced in the plant itself, e.g., by controlled combustion in a hot-gas generator and the recirculation of the gas. Such hot-gases most often consist of nitrogen, carbon dioxide, and water vapour. Normally such combustion gases are not clean enough for being used with food and feed materials, pharmaceuticals, etc.

\subsubsection{Dust Concentration Outside Explosive Range}

Ideally, one could avoid dust explosions by running the process in such a way that explosible dust concentrations were avoided. However, in practice, this is difficult in most cases, because the dust concentration inside the process equipment most often varies in unpredictable and uncontrollable ways, in particular during accidental dust explosions.

\subsubsection{Adding Inert Dust}

This principle is used in coal mines, by providing sufficient quantities of stone dust, either as a layer on the mine gallery floor or on shelves, etc. The blast that will always precede the flame in a dust explosion will then entrain the stone dust and coal dust simultaneously and form dust mixtures that are non-combustible in air. Then the dust flame, when arriving at these mixed clouds, will be quenched. In other industries than mining, adding inert dust is seldom applicable, due to product contamination and other problems.

\subsection{Preventing Ignition Sources}

\subsubsection{Overview}

Scholl [17] distinguished between two categories of ignition sources. The first, organizational ignition sources, can largely be prevented by enforcing adequate working routines. They include smoking, open flames, welding (gas and electric), cutting (gas and rotating disc), and grinding. The second category, the operational ignition sources, arise within the process itself, and they include open flames, hot surfaces, self-heating and smouldering nests, exothermic decomposition, heat from mechanical impact between solid bodies (metal sparks/hot-spots), electric sparks/arcs, and electrostatic discharges.

\subsubsection{Preventing Self-Heating, Smouldering and Burning in Large Dust Deposits}

The risk of self-heating in powder/dust deposits depends on the inherent properties of the material. Therefore, any possible disposition to self-heating should be known or assessed for any material before admitting it to storage silos, or to other parts of the plant where conditions are favourable for self-heating and a further temperature increase to smouldering and burning. Eckhoff $[1,2]$ described various means of preventing self-heating and self-ignition in powder deposits.

\subsubsection{Preventing Ignition by Open Flames/Hot Gases}

Most of the potential ignition sources of the open flame type can be avoided by enforcing adequate organizational procedures and routines. This, in particular, applies to the prohibition of smoking and other use of lighters and matches, and to the enforcement of strict rules for performing hot work.

\subsubsection{Preventing Ignition by Hot Surfaces}

Hot surfaces may occur in industrial plants, both intentionally and unintentionally. The first category includes external surfaces of hot process equipment, heaters, dryers, steam pipes, and electrical equipment. The equipment where hot surfaces may be generated unintentionally include engines, blowers and fans, mechanical conveyors, mills, 
mixers, bearings, and unprotected light bulbs. Hot surfaces can also arise from hot work. Eckhoff [1,2] provided further details.

\subsubsection{Preventing Ignition of Dust Clouds by Smouldering Nests}

Infrared radiation detection and subsequent extinction of smouldering nests and their fragments during pneumatic transport in dust extraction ducts can be an effective means of preventing fire and explosions in downstream equipment, for example, dust filters. Normally, the transport velocity in the duct is known, and this allows for effective extinction by synchronized injection of a small amount of extinguishing agent, just when the smouldering/burning nest or fragment passes the injection nozzles that are located at the optimal distance downstream of the detection point. Most often, water is used extinguishing agent, and it is applied as a fine mist. Such extinction systems are quite common in the wood industries, but also to some extent in the food and feed and some other industries.

\subsubsection{Preventing Ignition by Heat from Accidental Mechanical Impacts}

Mechanical impacts can produce two different kinds of potential ignition sources. The first is small flying fragments/particles of burning solid material, most often metal, which have been torn away from some bulk material and got ignited by the impact energy. The second potential ignition source from such impacts is so-called hot-spots, where the impacting bodies touch. In rotating machinery, impacts may repeatedly occur at the same point on one or both of the impacting bodies and this may give rise to hot-spots of appreciable size and temperature. In such cases the hazardous source of ignition will rather be a hot surface than a metal particle spark.

\subsubsection{Preventing Ignition by Electric Sparks and Arcs and Electrostatic Discharges}

Electric sparks and arcs due to breakage of live circuits can occur when fuses blow, in rotating electric machinery and when live leads are accidentally broken. The main rule for minimizing the risk of dust explosions due to such sparks and arcs is to stick to the current regulations for electrical installations in areas that contain combustible dust. The electrostatic hazard is more complex, and it has not always been straightforward to specify clearly defined design guidelines. Glor [5] recommended a series of useful measures.

\subsection{Mitigation of Dust Explosions Initiated in Spite of Preventive Measures}

\subsubsection{Reducing Sizes of Explosive Dust Clouds by Good Process Design}

Minimizing volumes of process equipment can be regarded as part of the quite new concept of inherently safer process design (discussed in Section 4, below). Volumes of process equipment should then not exceed the volumes that are needed by the process. Too large volumes can either be the result of inadequate design, or of the plant being used for another purpose than originally designed for.

Minimizing volumes of dust clouds generated at transfer points can also be considered as an application of the concept of inherently safer plants. Undesired dust clouds are practically always generated when powder/dust/pelletized material, etc. is falling freely under gravity. Therefore, whenever possible, transfer points should be designed to ensure that the powder/dust flows smoothly in bulk, rather than being dispersed as a dust cloud.

\subsubsection{Partial Inerting by Inert Gas}

This concept was discussed by Eckhoff [18] and implies that a smaller fraction of inert gas than that required for complete inerting is added to the air. In this way, the ignition sensitivity, the explosion violence, and the maximum constant-volume explosion pressure will be reduced, in some cases appreciably. This offers a new possibility for applying mitigatory measures, such as explosion venting or automatic explosion suppression, in situations where the explosion violence of the dust in air only is too severe to permit the use of such techniques. More research is needed to establish correlations between the 
oxygen content in the gas phase and various ignitability and explosibility parameters of various dusts.

\subsubsection{Explosion Isolation}

There are three main reasons for preventing dust explosion in one process unit from spreading to others via pipes and ducts. Firstly, there is always a desire to limit the extent of the explosion as far as possible. Secondly, a dust flame propagating in a duct between two process units can give rise to violent flame jet ignition of the dust cloud in the second volume. Pressure piling is the third main reason, which implies the increase of the pressure of the unburnt dust cloud in the downstream process unit(s) to above atmospheric pressure, due to the compression that is caused by the expansion of the hot combustion gases in the unit where the explosion starts, as well as in the connecting duct(s). Two categories of methods are used for obtaining explosion isolation. The first is passive methods activated by the propagating explosion itself. The second category requires a separate flame/pressure sensor system, which triggers a separately powered system for operating the isolation mechanism. For obvious reasons, the passive systems are generally preferable, provided they are suitable for the actual purpose.

\subsubsection{Dust Explosion Venting}

Main principle

Dust explosion venting is a method of preventing the pressure being developed by a dust explosion inside a compartment/process unit from exceeding the pressure that the compartment can withstand. This is accomplished by providing a pressure relief opening in the compartment wall. Under normal process conditions, the opening remains closed by a comparatively weak cover that will burst or open in the event of a dust explosion inside the compartment.

\section{Parameters influencing the sizing of dust explosions vents}

- Volume of compartment.

- Length/diameter ratio of compartment.

- Maximum over-pressure $P_{\text {red }}$ that the compartment wall(s) can withstand.

- Static opening over-pressure $P_{\text {stat }}$ of vent cover.

- Mass of vent cover.

- Burning rate of dust cloud.

Explosion venting prevents the rupture of the entire compartment, in which the explosion takes place. However, significant hazards remain. These include:

- Ejection of strong flame jets and flame balls from the vent opening.

- Emission of blast waves from the vent opening.

- Reaction forces on the equipment caused by the venting process.

- Emission of solid objects (vent panels and other possible objects).

- Emission of toxic combustion products.

Vent ducts and quenching tubes

The use of vent ducts is one solution to the flame jet/flame ball problem. This implies that a duct of cross-sectional area at least equal to the vent area is mounted between the vent and a place where a strong flame jet/flame ball will not present any hazard. However, vent ducts will generally increase the resistance to the outflow from the vent. Consequently, adding a vent duct increases the maximum explosion pressure in the vented vessel. However, the performance of vent ducts is complex. The pressure may increase with increasing vent duct length, at least up to some length, depending on where in the system ignition of the dust cloud takes place. Sharp duct bends also tend to increase the maximum explosion pressure in the vented system. In some applications where vent ducts are difficult to implement, the quenching tube, invented by Alfert and Fuhre [19], may provide a workable solution to in-house dust explosion venting. 


\subsubsection{Explosion-Pressure-Resistant Design}

In some special cases, for example, when producing and handling highly toxic materials, the full confinement of potential accidental dust explosions is required. Subsequently, all process equipment containing such materials must be able to withstand an internal dust explosion.

\subsubsection{Automatic Explosion Suppression of Dust Explosions}

The basic working principle of systems for automatic explosion suppression is the very fast automatic injection of an extinguishing agent into the part of the dust cloud where the dust flame starts to develop. The method works well for most organic dusts. However, it is not clear to what extent the method is also applicable to very fast-burning dust clouds. Automatic explosion suppression systems are comparatively expensive both to purchase and run.

By combining explosion venting and automatic explosion suppression, the maximum explosion pressure inside the process equipment can, in some cases, be reduced to a level significantly lower than the level that can be obtained by explosion venting only.

Moore and Bartknecht [20] conducted dust explosion suppression experiments in large vessels of volumes up to $250 \mathrm{~m}^{3}$ and they were able to demonstrate that successful suppression of explosions in clouds of organic dusts is possible in such large volumes.

Traditionally, halogenated hydrocarbons (halons) were used as flame- extinguishing agents (suppressants) in automatic dust explosion suppression systems. However, even before the environmental problems that were caused by these chemicals became a major issue. Bartknecht [9] found that powder suppressants, such as $\mathrm{NH}_{4} \mathrm{H}_{2} \mathrm{PO}_{4}$, were, in general, much more effective for suppressing dust explosions than halons.

\subsubsection{Good Housekeeping (Dust Removal/Cleaning)}

The main prerequisite for disastrous secondary dust explosions in the process industries is that significant quantities of combustible dust have accumulated on floors, walls, shelves, beams, and process equipment in factory buildings. This means that the risk of extensive secondary explosions can be effectively eliminated if the outside of process equipment, and shelves, beams, walls, and floors of work rooms are kept free of dust.

Significant quantities of dust can accidentally accumulate outside process equipment, due, e.g., accidental bursting of sacks or bags or erratic discharge from silos or filters. In such cases it is important that the spilt dust be removed immediately. Appreciable quantities of dust can also accumulate outside process equipment over a long time, due to minor but steady leaks from process equipment. The risk of such dust leaks clearly increases if the working pressure inside a process unit is higher than ambient. The risk of dust leaks drops significantly if the unit is at a slightly lower than ambient pressure.

The use of compressed air for blowing spilled dust in workrooms away should be prohibited. By this method, dust is not removed, but only transferred to another location in the same room. Besides, a dust explosion can result if the dust concentration in the cloud that is generated is in the explosive range and an ignition source exists in the same location. Beck and Jeske outlined the requirements to mobile vacuum cleaners that are recommended in Germany at that time for removal of combustible dusts [21].

\section{A Catastrophic Aluminium-Alloy Dust Explosion in China in 2014}

\subsection{Introduction}

Eckhoff [1,2] reviewed a selection of case histories from various countries. The oldest was on a wheat flour explosion in 1785 in Turin, Italy. However, because of limited space, only a single case history has been included in the present short review. There are three good reasons for this choice. Firstly, the case occurred relatively recently. Secondly, it demonstrates the major-catastrophe potential of dust explosions. Thirdly, the ignition source initiating the explosion was not trivial. The catastrophe also demonstrated the huge 
destructive potential of secondary dust explosions that are caused by the re-dispersion of even thin layers of deposited dust.

\subsection{Some Key Event Data}

The present account is based on the extensive paper by Li et al. [22]. The catastrophic explosion occurred on 2 August 2014 in a large industrial plant in Kunshan, China. The sole objective of the plant was to grind and polish moulded metal parts. At the time of the explosion, aluminium-alloy wheel hubs for the car industry were ground and polished. 146 people lost their lives in the explosion. The direct economic loss of was about 350 million yuan. Apart from some very major coal dust explosion disasters in coal mines, this is probably one of the most serious industrial dust explosion catastrophes in human history.

\subsection{The Plant Struck by the Explosion}

The explosion occurred in a two-storey reinforced concrete-frame-structure process building of length $44 \mathrm{~m}$ and width $24 \mathrm{~m}$. The total floor area was approximately $2000 \mathrm{~m}^{2}$. The two floors were connected by open staircases at each end of the building. Thirty-two polishing production lines (16 on each floor) were arranged in parallel, as indicated in Figures 4 and 5. There were 12 working stations along each line, as also indicated in Figures 4 and 5 .

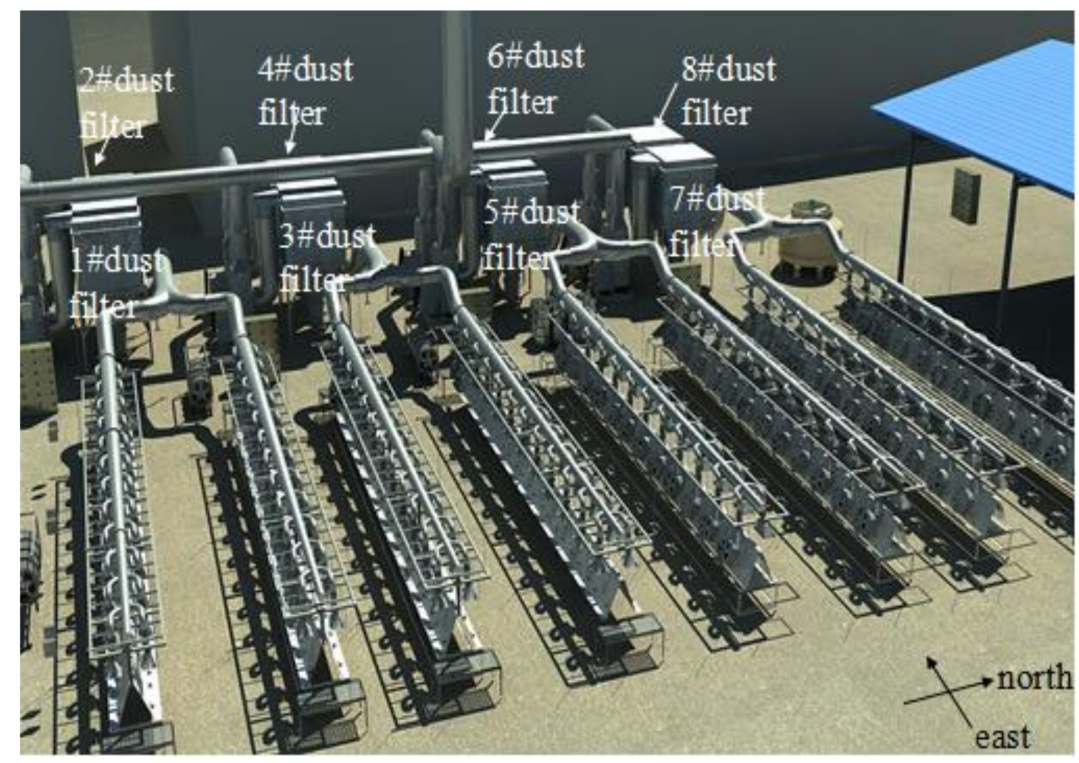

Figure 4. Production lines with workstations. From Li et al. (2016). Copyright (2016), with permission from Elsevier.

On the day before the explosion, 29 production lines were in operation, 13 on the first floor and 16 on the second floor. 348 workers were on duty. The polishing operations were conducted manually, as indicated in Figure 5. Electrically powered manual grinding guns were the main tools. Different grades of grinding heads and/or emery papers were used, depending on the finish quality required. Eight sets of similar dust collection systems were installed outside the main factory building to collect the metal dust from the polishing processes on the two floors in bag filters. The filters were supposed to be cleaned by automatic mechanical shaking at intervals. However, after the explosion accident, survivors told that, due to breakdown of the driving electric motor, the automatic shaking systems had been out of operation for a long time. Instead, workers had cleaned the bags manually every morning before commencing work by vibrating the carriage of the bags.

No special requirements addressing a possible dust explosion hazard had been enforced on the selection and installation of all the electrical equipment used in the plant. 
Neither the dust collectors or the dust extraction ducting, nor all of the electrical sockets and power distribution cabinets, had been adequately earthed.

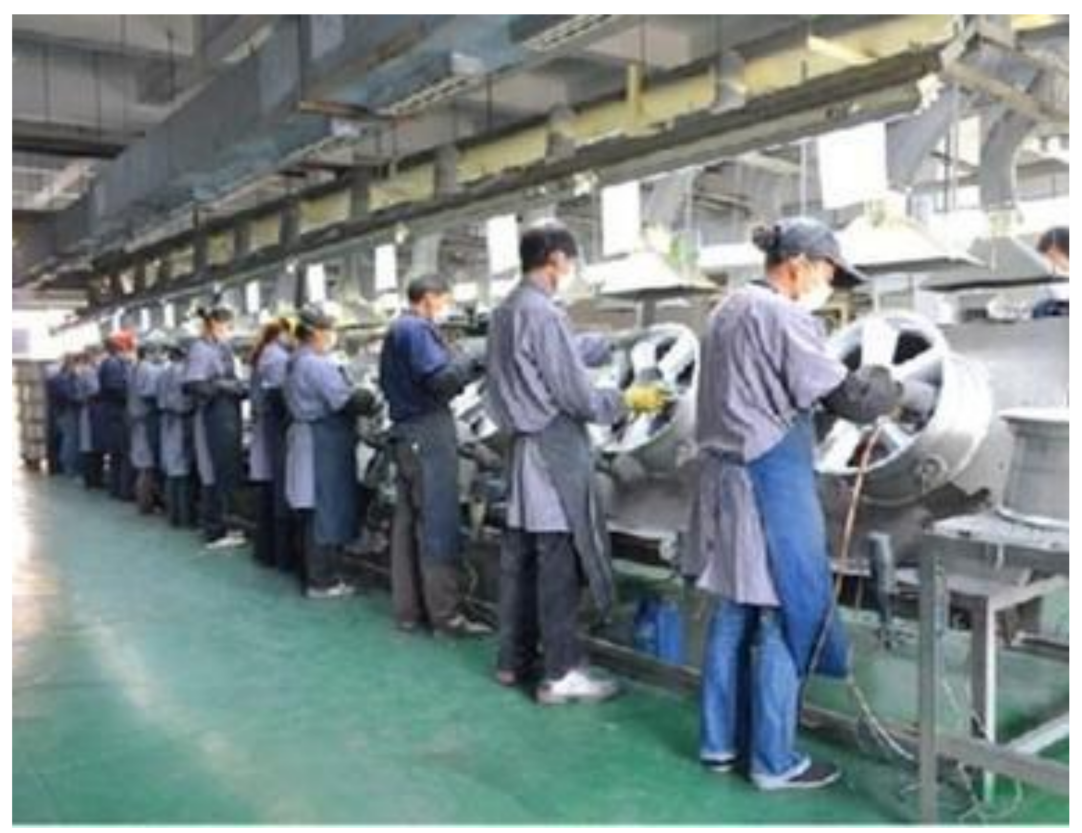

Figure 5. Workers on duty at the workstations. From Li et al. (2016). Copyright (2016), with permission from Elsevier.

\subsection{Plant Damage}

The catastrophe occurred in the morning when normal hub polishing activity has been going on for about half an hour. A video camera approximately $500 \mathrm{~m}$ away from the building struck by the explosion revealed a sequence of several explosions lasting for about 5-7 s. This included a series of eight distinct successive explosions that could be identified on the video recording as violent "mushroom-shaped" dust/smoke clouds being expelled abruptly from each of the eight dust collectors. All of the windows in the first floor of the afflicted building were shattered and blown to the outside. The window frames were completely deformed. Two-thirds of the southern wall of the building collapsed. Window frames were blown out of the eastern wall, and two air conditioners that were located at this wall were partly detached from the wall. The blasts also lifted some of the light colour steel roof of the second floor, and broke all the windows, surprisingly, the glasses scattered on the ground inside. Two thirds of the southern wall of the building collapsed. Almost all the process equipment in the workshop was torn apart. Figure 6 shows the total damage of the production lines on the second floor. The explosion tore apart the entire system of dust extraction ducts on both floors. 


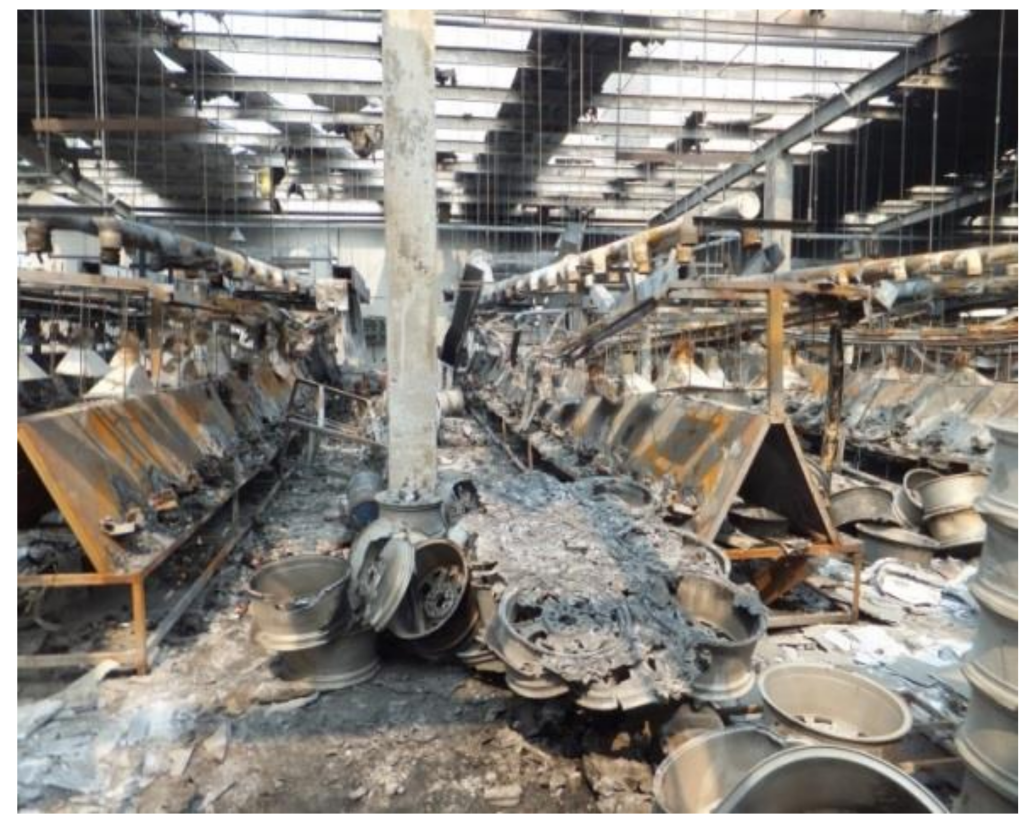

Figure 6. Destroyed process lines on the second floor. From Li et al. (2016). Copyright (2016), with permission from Elsevier.

\subsection{Probable Ignition Source of the Initial Primary Explosion}

It appeared that it was impossible to identify any obvious ignition source. However, it was observed that the dust collecting barrel below the filter of the production line where the explosion had apparently started had its bottom completely blown out. Careful examination of the damaged barrel revealed a different-looking hole that had most probably been caused by corrosion over a long period prior to the explosion. Both the filter and barrel underneath were located outdoors. It had been raining heavily for two days before the explosion accident, and it still rained lightly at the time of the catastrophe. Rainwater had probably entered the barrel through the corroded hole and moistened the aluminium-alloy dust in the barrel. This water probably initiated the process, leading to self-ignition of the aluminium-alloy dust in the barrel according to the reaction equation:

$$
2 \mathrm{Al}+6 \mathrm{H}_{2} \mathrm{O}=2 \mathrm{Al}(\mathrm{OH})_{3}+3 \mathrm{H}_{2}+\text { heat }
$$

Laboratory experiments that were conducted after the explosion accident gave support to this hypothesis. It was found that the unburnt aluminium-alloy dust that was retrieved from the barrel after the explosion was contaminated by some organic material from the wheel hub grinding/polishing process (polishing waxes etc.). This made the dust "fluffy" and gave it a significantly lower bulk density than those of deposits of pure dry aluminium alloy dust. The contaminated dust also had a lower thermal conductivity than would be expected for pure aluminium-alloy dust.

A significant detail was observed during the laboratory experiments: after the selfignition process had developed fully inside the wet contaminated metal dust deposit, open flames lasting for about $10 \mathrm{~s}$ were observed on top of the deposit surface. It seems reasonable to assume that these flames were due to the burning of the hydrogen released according to equation (1), possibly mixed with pyrolysis gases from the organic matter in the deposit. Such a flame probably ignited the cloud of aluminium alloy dust falling down from the filters in the dust collector during the shaking of the filters. The significant burning of hydrogen inside the dust in the barrel, before the combustion zone reached the powder surface at the top, was probably excluded by the free passage between the dust particles being significantly smaller than the quenching distance of hydrogen in air (about $0.5 \mathrm{~mm}$ at atmospheric pressure). 


\subsection{Recommended Actions for Preventing and Mitigation Similar Disasters}

The general ignorance of the potential risk of dust explosions in industries producing fine metal dusts as a small-quantity waste product only was identified as an important root cause of this catastrophic accident. Even in such plants, excessive deposits of waste dust can build up over a long time on floors, shelves, beams, and process equipment. Therefore, good regular housekeeping to remove layers of accumulated waste dust is a most effective and practical way of preventing and mitigating serious secondary metal dust explosions in such plants. In addition, ignition source prevention and explosion isolation between dust collecting systems and workrooms are important means for minimizing the risks of such explosions.

\section{Review of Some Current Issues Related to Fighting of Dust Explosions}

\subsection{National and International Standardization}

There is a number of national and international standards specifying measures for preventing and mitigating industrial dust explosions, and methods for the testing of ignitability and explosibility of dusts. The central standardization organizations include CEN (European Union), IEC (international), NFPA, and ASTM (USA). New standards are introduced, and old ones continuously updated by all of these organizations.

\subsection{Modelling of Dust Flame Propagation in Process Environments}

This is by no means a trivial task. Skjold [23] reviewed some of the advancements that have made over the last years, mainly based on the computational-fluid-dynamics concept (CFD) used successfully for modelling flame propagation processes in accidental gas explosions. However, because of the two-phase nature of dust clouds, dust explosions are much more complex to model than explosions in premixed gases. Sub-models of the influence of the combustion individual dust particles on the global flame propagation will have to be included. Sundaram et al. [24] developed a theory of ignition and combustion of $\mathrm{nm}$ and $\mu \mathrm{m}$ aluminium particles. Serrano et al. [25] carried out experiments in a closed 20-1 vessel, as well as a computational CFD-DEM analysis, of the dispersion and combustion of clouds in air of wheat starch and carbon black powders.

\subsection{Inherently Safer Process Design}

Amyotte [26] gave the following (slightly edited) definition of this rather new concept in a dust explosion context: Inherently safer process design is a proactive approach in which hazards are eliminated or lessened so as to reduce risks with decreased reliance on "add-on" devices and "add on" procedural measures". The general concept of inherently safer process design has been developed over the past 40 or so years, beginning with the pioneering work of the late professor Trevor Kletz. This was largely his response to the catastrophic cyclohexane explosion (vapour and mist) at Flixborough, UK, in 1974. Four basic principles to facilitate inherent safety implementation in industry have over the years been developed and gained widespread acceptance, as pointed out by Amyotte [26]. Amyotte et al. [27] and Chapter 13, in Kletz and Amyotte [28], gave numerous examples of application of the four basic principles in the effort to reduce dust explosion risks. Amyotte and Eckhoff [29] also discussed specific technical measures that must be taken when applying the four basic principles to dust explosion risks in the process industries. The four basic principles, as defined by Amyotte [26], are:

Minimization: use smaller quantities of hazardous materials when the use of such materials cannot be avoided or eliminated. Perform a hazardous procedure as few times as possible when the procedure is unavoidable.

Replacement: replace a hazardous substance with a less hazardous material or replace a processing route with one that does not involve hazardous material. Replace a hazardous procedure with one that is less hazardous.

Moderation: use hazardous materials in their least hazardous forms or introduce processing options that involve less severe processing conditions. 
Simplification: design processes, processing equipment, and procedures to eliminate possible errors that are associated with excessive use of add-on safety features and protective devices.

Eckhoff [30] gave an example of substitution in terms of replacing funnel-flow silos by mass flow silos in powder storage.

\subsection{Generation, Ignition and Explosion of Nm-Particle Dust Clouds}

Eckhoff [30] discussed of this topic. An increasing range of new nm-particle types are currently produced for use in various consumer products, ranging from cosmetics, sunscreens, toothpastes, pharmaceuticals, and clothing, to electronics, plastics, and tires. Over the last decades, this development has escalated.

Bouillard et al. [31] were probably amongst the first to ask whether dust clouds of nm-particles of a combustible material present an enhanced dust explosion hazard when compared with dust clouds in the air of the same materials of $\mu \mathrm{m}$ size particles. More than 140 years ago, Weber [32], a pioneer in dust explosion research in Germany, pointed at the close relationship between dust cohesion and dust dispersibility. Eckhoff [1] presented a highly idealized definition of an upper theoretical limit of dust/powder dispersibility. Green and Lane [33] discussed the important concept of particle coagulation in dust clouds. This was re-emphasized by Eckhoff [34]. With nm size particles and explosible particle mass dust concentrations, coagulation by inter-particle collisions is extremely fast. However, as discussed below, MIEs of clouds in air of some metal powders can be significantly lower for $\mathrm{nm}$ particles than for $\mu \mathrm{m}$ particles.

Around and just after year 2000 most of the publications on production of combustible nm-particles of carbon and various metals, referred to production methods and facilities of laboratory or small pilot scales. Kónya et al. [35] described a method for the production of batches of up to $100 \mathrm{~g}$ of carbon nano-tubes. However, some years later Wei et al. [36] described a pilot plant concept that is capable of producing high-purity multi-walled carbon nano-tubes at a yield of some $\mathrm{kg} /$ hour, which would mean 10-20 tons per year on a continuous-production basis. With such quantities, the dust explosion hazard would become a concern. It may well be that, since the paper by Wei et al., genuine large-scale plants for production of various types of nm particles have become a reality.

The experiments by Wu et al. [37] showed that minimum electric spark ignition energies (MIEs) of dust clouds in air nm-powders of both titanium and iron were considerably lower than the MIEs of $\mu \mathrm{m}$-powders of the same materials. Holbrow et al. [38] also found quite low MIEs (<1 mJ) for clouds in air of some nm metal powders. Eckhoff [34] suggested that this may be caused by thermal-stress break-up of particle agglomerates close to the very hot spark plasma.

Existing national and international standard methods for MIE determination of dust clouds have a lower spark energy limit of about $1 \mathrm{~mJ}$, Therefore, Wu et al. [37] called for a new generator capable of generating synchronized electric sparks of energies $<1 \mathrm{~mJ}$. Randeberg et al. [39] reported work in this direction. However, it turned out that their spark generator needed further development to become suitable for the intended purpose. This was discussed by Eckhoff and Olsen [40], and Olsen et al. [41] described an electronic solution to the problem.

Using the standard 20-litre explosion bomb, Vignes et al. [42] determined maximum explosion pressures $\left(P_{\max }\right)$ and maximum rates of rise of explosion pressures $(\mathrm{dP} / \mathrm{dt})_{\max }$ of three kinds of nm-particle powders. For aluminium, it was found that, down to particle sizes of the order of $1 \mu \mathrm{m}$, both $\mathrm{P}_{\max }$ and $(\mathrm{dP} / \mathrm{dt})_{\max }$ increased systematically with decreasing particle size. However, when the particle size decreased further down to the genuine nm-particle region (particles smaller than $100 \mathrm{~nm}$ ), both $\mathrm{P}_{\max }$ and $(\mathrm{dP} / \mathrm{dt})_{\max }$ decreased. Eckhoff [34] suggested that the reason could be very rapid coagulation of the tiny primary $\mathrm{nm}$ particles before the dust cloud became ignited. Holbrow et al. [38] reported on similar results from experiments in their specially constructed two-litre closed explosion bomb. 
Wu et al. [43] investigated the ignition sensitivity to friction and impact of some $\mathrm{nm}$ particle metal powders during conveyance from the pre-compressed dust dispersion reservoir of a standard 20-1 Siwek/Kühner-type explosion bomb into the bomb itself. Bouillard et al. [44] arrived at the same conclusion as Wu et al. [37] regarding the MIEs of $\mathrm{nm}$ powders. They also compared the explosion violence of clouds in air of $\mu \mathrm{m}$ and $\mathrm{nm}$ titanium powders using various standard test equipment. Wu et al. [45] studied whether ignition would take place during the production of nm powders in air jet mills They worked with a pilot size air-jet mill producing nm powders of titanium and iron. The mass of material in the mill was $20 \mathrm{~kg}$. Turkevich et al. [46] investigated the ignition and explosion properties of clouds in air of a range of carbonaceous $\mathrm{nm}$ powders, including carbon black, graphene, and graphite Krietsch et al. [47] presented the results from experiments with several un-oxidized metallic nm powders (aluminium, iron, zinc, titanium, copper) in a modified 20-1 Siwek bomb.

\section{Conclusions}

The first question addressed in this paper is: What is a dust explosion? Then, essential aspects of the dust explosion phenomenon are outlined. These include materials that can give dust explosions, factors influencing the ignitability and explosibility of dust clouds, combustion processes of dust clouds, ignition sources that can initiate dust explosions, primary and secondary dust explosions, dust flash fires, explosions of "hybrid mixtures", and detonation of dust clouds. Subsequently, the case history of a comparatively recent industrial dust explosion catastrophe in China is outlined, which demonstrates the vast destructive potential of dust explosions. Finally, the paper focuses on some current "hot" research topics. More research and development are needed on all of the topics reviewed in this paper.

Author Contributions: Conceptualization and writing by R.K.E., case history by G.L. All authors have read and agreed to the published version of the manuscript.

Funding: This research was partly funded by the National Natural Science Foundation of China (No. 51774068)

Informed Consent Statement: Informed consent was obtained from all subjects involved in the study.

Data Availability Statement: Data available in a publicly accessible repository.

Acknowledgments: As a professor emeritus at the Department of physics and technology at the University of Bergen, Norway, R. K. Eckhoff wishes to express his indebtedness to this Department for so generously allowing him to keep a work place there and for providing him with the infrastructure that makes it possible for him to carry on with his writing. Gang Li wishes to express his gratitude to the National Natural Science Foundation of China (No. 51774068) for its valuable financial support.

Conflicts of Interest: The authors declare no conflict of interest.

\section{References}

1. Eckhoff, R.K. Dust Explosions in the Process Industries, 3rd ed.; Gulf Professional Publishing/Elsevier: Hoboken, NJ, USA, 2003; ISBN 0-7506-7602-7.

2. Eckhoff, R.K. Explosion Hazards in the Process Industries, 2nd ed.; Gulf Professional Publishing: Houston, TX, USA, 2016; ISBN 9780-12-803273-2.

3. Eckhoff, R.K. Dust Explosion Fundamentals; Methods in Chemical Process Safety; Elsevier Inc.: Amsterdam, The Netherlands, 2019; Volume 3, Chapter 2; ISBN 2468-6514.

4. Leuschke, G. Beitrage zur Erforschung des Mechanismus der Flammenausbreitung in Staubwolken. Staub 1965, 25, 180-186.

5. Glor, M. Electrostatic Hazards in Powder Handling; Research Studies Press Ltd.: Devon, UK; John Wiley \& Sons Inc.: Hoboken, NJ, USA, 1988.

6. Lüttgens, G.; Glor, M. Understanding and Controlling Static Electricity; Expert Verlag: Ehningen bei Böblingen, Germany, 1989.

7. Bartknecht, W. Explosionsschutz—Grundlagen und Anwendung; Springer: Berlin/Heidelberg, Germany, 1993; ISBN 3-540-55464-5.

8. Proust, C. Ignition of dust-air mixtures by a laser beam. In Proceedings of the 7th International Coll. Dust Explosions, Bergen, Norway, 23-26 June 1996; GexCon AS (previously CMR): Bergen, Norway, 1996.

9. Bartknecht, W. Explosionen-Ablauf und Schutzmassnahmen; Springer: Berlin/Heidelberg, Germany, 1978; ISBN 3-540-08675-7. 
10. Engler, C. Beitrage zur Kenntniss der Staubexplosionen; Springer: Berlin/Heidelberg, Germany, 1885; pp. 171-173.

11. Engler, C. Einfacher Versuch zur Demonstration der gemischten Kohlenstaub- und Gasexplosionen. Chem. Ztg. 1907, 28, 358-359.

12. Nagy, J.; Portman, W.M. Explosibility of Coal Dust in an Atmosphere Containing a Low Percentage of Methane; Rep. Inv. 5815; US Bureau of Mines: Washington, DC, USA, 1961.

13. Franke, H. Bestimmung der Mindestzündenergie von Kohlenstaub/Methan/Luft-Gemischen (Hybride Gemische). VDI Ber. 1978, 304, 69-72.

14. Pellmont, G. Explosions- und Zündverhalten von Hybriden Gemischen aus Brennbaren Stäuben und Brenngasen. Ph.D. Thesis, ETH Zürich, Zürich, Switzerland, 1979.

15. Addai, E.K.; Gabel, D.; Krause, U. Experimental investigation of the minimum ignition temperature and the lower explosible/flammable fuel concentration, of clouds of hybrid mixtures of a combustible dust and a combustible gas or solvent vapour. J. Hazard. Mater. 2016, 301, 314-326. [CrossRef]

16. Tulis, A.J. Initiation and Propagation of Detonation in Unconfined Clouds of Aluminium Powder in Air. In Proceedings of the 9th International Seminar on Pyrotechnics, Colorado Springs, CO, USA, 6-10 August 1984.

17. Scholl, E.W. Vorbeugender Explosionsschutz durch Vermeiden von Wirksamen Zündquellen; VDI-Berichte; VDI-Verlag GmbH: Düsseldorf, Germany, 1989; Nr. 701; pp. 477-489.

18. Eckhoff, R.K. Partial inerting-An additional degree of freedom in dust explosion protection. J. Loss Prev. Process Ind. 2004, 17, 187-193. [CrossRef]

19. Alfert, F.; Fuhre, K. Flame and Dust Free Venting of Dust Explosions by Means of a Quenching Pipe; Report No. 89/25820-1; Chr. Michelsen Institute: Bergen, Norway, 1989.

20. Moore, P.E.; Bartknecht, W. Extending the limits of explosion suppression systems. Staub Reinhalt. Luft 1987, 47, $209-213$.

21. Beck, H.; Jeske, A. Prüfung Fahrbarer Industriesstaubsauger zum Einsatz in Durch Staubexplosionsgefährdeten Bereichen, VDI Berichte No.701; VDI-Verlag GmbH: Düsseldorf, Germany, 1989; pp. 881-897.

22. Li, G.; Yang, H.-X.; Yuan, C.-M.; Eckhoff, R.K. A catastrophic aluminium-alloy dust explosion in China. J. Loss Prev. Process Ind. 2016, 39, 121-130. [CrossRef]

23. Skjold, T. Dust explosion modelling: Status and prospects. Part. Sci. Technol. 2018, 36, 489-500.

24. Sundaram, D.S.; Puri, P.; Yang, V. A general theory of ignition and combustion of nano- and micron-sized aluminium particles. Combust. Flame 2016, 169, 94-109. [CrossRef]

25. Serrano, J.; Pico, P.; Amin, M.A.; Torrado, D.; Murillo, C.; Bardin-Monnier, N.; Ratkovich, N.F.; Dufaud, O. Experimental and CFD-DEM study of the dispersion and combustion of wheat starch and carbon-black particles during the standard 20-1 sphere test. J. Loss Prev. Process Ind. 2020, 63, 103995. [CrossRef]

26. Amyotte, P.R. An Introduction to Dust Explosions. Understanding the Myths and Realities of Dust Explosions for a Safer Work Place; Butterworth-Heinemann, an Imprint of Elsevier Inc.: Amsterdam, The Netherlands, 2013; ISBN 978-0-12-397007-7.

27. Amyotte, P.R.; Pegg, M.J.; Khan, F.I. Application of inherent safety principles to dust explosion prevention and mitigation. Process Saf. Environ. Prot. 2010, 87, 35-39. [CrossRef]

28. Kletz, T.; Amyotte, P.R. Process Plants. A Handbook for Inherently safer Design, 2nd ed.; CRC Press: Boca Raton, FL, USA; Taylor \& Francis Group: Abingdon, UK, 2010.

29. Amyotte, P.R.; Eckhoff, R.K. Dust explosion causation, prevention and mitigation: An overview. J. Chem. Health Saf. 2010, 17, 15-28. [CrossRef]

30. Eckhoff, R.K. Fighting dust explosions in the process industries. J. Loss Prev. Process Ind. 2020, 67, 104225. [CrossRef]

31. Bouillard, J.; Vignes, A.; Dufaud, O.; Perrin, L.; Thomas, D. Explosion risks from nano-materials. In Nanosafe 2008: Proceedings of the International Conference on Safe Production and Use of Nano-Materials, Grenoble, France, 3-7 November 2008; Journal of Physics: Conference Series 170 023032; IOP Publishing: Bristol, UK, 2009.

32. Weber, R. Preisgekrönte Abhandlung über die Ursachen von Explosionen und Bränden in Mühlen, sowie über die Sicherheitsmassregeln zur Verhütung derselben. Verh. Ver. Gew. Fliess. Berl. 1878, 83-103.

33. Green, H.L.; Lane, W.R. Particulate Clouds: Dusts, Smokes and Mists, 2nd ed.; E. \& F.N. Spon Ltd.: London, UK, 1964; Catalogue No. 16/0853/7.

34. Eckhoff, R.K. Does the dust explosion risk increase when moving from $\mu \mathrm{m}$-particle powders to powders of nm-particles? J. Loss Prev. Process Ind. 2012, 25, 448-459. [CrossRef]

35. Kónya, Z.; Vesselenyi, I.; Niesz, K.; Kukovecz, A.; Demortier, A.; Fonseca, A.; Delhalle, J.; Mekhalif, Z.; Nagy, J.B.; Koós, A.A.; et al. Large scale production of short functionalized carbon nanotubes. Chem. Phys. Lett. 2002, 360, 429-435. [CrossRef]

36. Wei, F.; Zhang, Q.; Qian, W.-Z.; Yu, H.; Wang, Y.; Luo, G.-H.; Xu, G.-H.; Wang, D.-Z. The mass production of carbon nano-tubes using a nano-agglomerate fluidized bed reactor: A multiscale space-time analysis. Powder Technol. 2008, 183, 10-20. [CrossRef]

37. Wu, H.-C.; Chang, R.-C.; Hsiao, H.C. Research on minimum ignition energy for nano titanium powder and nano iron powder. J. Loss Prev. Process Ind. 2009, 22, 21-24. [CrossRef]

38. Holbrow, P.; Wall, M.; Sanderson, E.; Bennett, D.; Rattigan, W.; Bettis, R.; Gregory, D. Fire and Explosion Properties of Nanopowders, HSE Report RR782. 2010.

39. Randeberg, E.; Eckhoff, R.K. Measurement of minimum ignition energies of dust clouds in the $<1 \mathrm{~mJ}$ region. J. Hazard. Mater. 2007, 149, 237-244. [CrossRef] 
40. Eckhoff, R.K.; Olsen, W. A new method for generation of synchronized capacitive sparks of low energies. Reconsideration of previously published findings. J. Electrost. 2010, 68, 73-78. [CrossRef]

41. Olsen, W.; Arntzen, B.J.; Eckhoff, R.K. Electrostatic dust explosion hazards-Twowards a $<1 \mathrm{~mJ}$ synchronized-spark generator for determination of MIEs of ignition sensitive transient dust clouds. J. Electrost. 2015, 74, 66-72. [CrossRef]

42. Vignes, A.; Traoré, M.; Dufaud, O.; Perrin, L.; Bouillard, J.; Thomas, D. Assessing explosion severety of nanopowders with the 20 L sphere. In Proceedings of the 8th World Congress of Chemical Engineering, Montreal, QC, Canada, 23-27 August 2009.

43. Wu, H.-C.; Kuo, Y.-C.; Wang, Y.-H.; Wu, C.-W.; Hsiao, H.-C. Study on safe air transporting velocity of nano-grade alumimnium, iron and titanium. J. Loss Prev. Process Ind. 2010, 23, 308-311. [CrossRef]

44. Boillard, S.P.; Amyotte, P.R.; Kahn, F.I.; Dastidar, A.G.; Eckhoff, R.K. Explosibility of micron- and nano-size titanium powders. J. Loss Prev. Process Ind. 2013, 26, 1646-1654. [CrossRef]

45. Wu, H.-C.; Wu, C.-W.; Ko, Y.-H. Flame phenomena in nano-grinding process for titanium and iron. J. Loss Prev. Process Ind. 2014, 27, 114-118. [CrossRef]

46. Turkevich, L.A.; Dastidar, A.G.; Hachmeister, Z.; Lim, M. Potential explosion hazard of carbonaceous nano particles: Explosion parameters of selected materials. J. Hazard. Mater. 2015, 295, 97-103. [CrossRef]

47. Krietsch, A.; Scheid, M.; Schmidt, M.; Krause, U. Explosion behaviour of metallic nano powders. J. Loss Prev. Process Ind. 2015, 36, 237-243. [CrossRef] 